\title{
HUBUNGAN MUTASI KERJA DENGAN CAKUPAN PELAYANAN KESEHATAN DI PUSKESMAS BEUTONG KECAMATAN BEUTONG KABUPATEN NAGAN RAYA TAHUN 2014
}

\author{
Aida Yuddin ${ }^{1}$, Muhammad Iqbal Fahlevi ${ }^{2}$ \\ Fakultas Kesehatan Masyarakat, Universitas Teuku Umar, Meulaboh, Indonesia
}

\begin{abstract}
ABSTRAK
Mutasi tidak terlepas dari alasan untuk mengurangi rasa bosan pegawai kepada pekerjaan serta meningkatkan motivasi dan semangat kerja pegawai, selain itu untuk memenuhi keinginan pegawai sesuai dengan minat dan bidang masing-masing. Indikator turunnya semangat kerja antara lain rendahnya produktivitas, tingkat absensi pegawai tinggi, dan gaji rendah. Maka mempengaruhi semangat kerja pegawai pada suatu organisasi. Tujuan penelitian untuk mengetahui hubungan mutasi dengan cakupan pelayanan kesehatan pada Puskesmas Beutong Kecamatan Beutong Kabupaten Nagan Raya. Penelitian dilakukan pada tanggal 12 s/d 22 November tahun 2014. Desain penelitian adalah survey Analitik dengan pendekatan cross sectional. Terdiri dari variabel independen yaitu mutasi dan variabel dependen yaitu cakupan pelayanan kesehatan. Pengambilan sampel menggunakan teknik Total sampling. Pengumpulan data diperoleh dari data primer melalui kuesioner dan data sekunder melalui data Puskesmas Beutong. Analisa data menggunakan uji statistik Chi square.
\end{abstract}

Berdasarkan hasil penelitian dengan sampel 19 responden yang diwawancarai, 9 responden $(47,4 \%)$ menyatakan tidak dilakukan mutasi dan cakupan pelayanan kesehatannya tidak tercapai. Sedangkan 37 responden yang menyatakan ya dilakukan mutasi sebanyak 34 responden $(19,9)$ serta cakupan pelayanan kesehatannya tercapai. Dari hasil perhitungan Chi Square pada derajat kepercayaan $95 \%(\dot{\alpha}=0,05)$ diketahui bahwa nilai $p$ value adalah $(0,001)<\alpha(0,05)$. Maka Ha gagal ditolak sehingga ada hubungan antara mutasi dengan cakupan pelayanan kesehatan. Diharapkan kepada Kepala Puskesmas Beutong untuk memperhatikan keinginan dan kemauan bekerja seseorang yang mempunyai tujuan tertentu yang ingin dicapai. Diharapkan kepada seluruh pegawai di Puskesmas Beutong berfikir secara positif terhadap kebijakan mutasi yang diterapkan oleh kepala Puskemas Beutong.

Kata Kunci : Mutasi, Pegawai, Motivasi, Pelayanan Kesehatan

Pembangunan pada hakekatnya adalah kesadaran atau keinsyafan untuk melakukan kegiatan memperbaiki, mendirikan bahkan menumbuhkan serta meningkatkan daya upaya yang mengarah kepada keadaan yang lebih baik dengan dilandasi oleh semangat, kemauan dan tekad yang tinggi yang bertujuan untuk 
melakukan kegiatan-kegiatan yang bersifat memperbaiki dan meningkatkan kesejahteraan rakyat Indonesia pada umumnya (Hasibuan, 2008).

Tujuan tersebut baru dapat dicapai apabila pembangunan nasional dilaksanakan secara menyeluruh dengan pemanfaatan sumber daya manusia dan sumber daya bukan manusia, serta pelaksanaan pembangunan disegala bidang, terencana, terarah, bertahap dan berkesinambungan. Salah satu bidang tersebut adalah pembangunan manusia seutuhnya. Dalam hal ini keberhasilan pembangunan tergantung pada aspek manusianya yakni sebagai pemimpin, pelaksana dan pengelola sumber daya yang ada dalam nagara, yang dalam hal ini adalah Pegawai Negeri Sipil (PNS) (Hasibuan, 2008).

Pegawai Negeri Sipil (PNS) pada Puskesmas Beutong Kecamatan Beutong Kabupaten Nagan Raya yang merupakan aparatur negara yang menyelenggarakan pemerintahan dalam melaksanakan pembangunan nasional merupakan tulang punggung pemerintah. Kelancaran penyelenggaraan pemerintahan dan pelaksanaan pembangunan nasional terutama tergantung pada kesempurnaan aparatur negara baik ditingkat pusat maupun ditingkat daerah. Dalam ragka mencapai tujuan nasional sebagaimana dikemukakan di atas, diperlukan adanya pegawai negeri sipil yang penuh kesediaan dan ketaatan kepada Pancasila, Undang-Undang Dasar 1945, negara dan pemerintah serta bersatu padu, bermental baik, berwibawa, kuat berdaya guna, bersih, berkualitas tinggi dan sadar akan tanggung jawabnya sebagai unsur aparatur Negara, abdi Negara dan abdi masyarakat. Dengan adanya Peraturan Pemerintah Nomor 43 Tahun 1999 tentang pokok-pokok kepegawaian, dan tentang wewenang pengangkatan, pemindahan dan pemberhentian pegawai negeri sipil diatur di dalam Peraturan Pemerintah Nomor 96 Tahun 2000. Kedua Peraturan perundang-undangan tersebut merupakan pedoman pelaksanaan mutasi kepegawaian di setiap instansi pemerintah umum dan daerah terutama pada Puskesmas Beutong Kecamatan Beutong Kabupaten Nagan Raya .

Menurut Peraturan Pemerintah Nomor 43 Tahun 1999, bahwa yang termasuk pegawai pegawai negeri sipil adalah mereka yang setelah memenuhi syarat-syarat yang ditentukan dalam peraturan perundang-undangan yang berlaku, diangkat oleh pejabat yang berwenang dan diserahi tugas Negara lainnya yang ditetapkan berdasarkan satu peraturan perundang-undangan dan digaji menurut peraturan perundang-undangan yang berlaku. Untuk mewujudkan Pegawai Negeri Sipil (PNS) yang sempurna sebagaimana 
dimaksud di atas, maka pegawai negeri sipil perlu dibina dengan sebaik-baiknya dan diadakan pengembangan.

Tujuan pembinaan dan pengembangan (Fathoni, 2006) tersebut diharapkan agar setiap pegawai yang ada dalam organisasi yang bersangkutan dapat memberikan prestasi kerja yang sebaik-baiknya sehingga benar-benar dapat berfungsi sebagai penghasil kerja yang tepat guna sesuai dengan sasaran organisasi yang hendak dicapai, terwujudnya hubungan yang serasi antara atasan dan bawahan serta terwujudnya pegawai-pegawai yang setia dan taat kepada Pancasila, Undang-Undang Dasar 1945, Negara dan Pemerintah, sehingga pegawai hanya mengabdi kepada kepentingan negara dan masyarakat, demi terwujudnya aparatur yang bersih dan berwibawa. Salah satu bentuk dari pengembangan terhadap pegawai negeri sipil adalah mutasi sebagai penjelmaan/ perwujudan dari dinamika organisasi yang dijadikan sebagai salah satu cara untuk mencapai tujuan organisasi.

Mutasi tidak terlepas dari alasan untuk mengurangi rasa bosan pegawai kepada pekerjaan serta meningkatkan motivasi dan semangat kerja pegawai, selain itu untuk memenuhi keinginan pegawai sesuai dengan minat dan bidang tugasnya masing-masing dimana dalam kegiatan pelaksanaan mutasi kerja sering disalah tafsirkan orang yaitu sebagai hukuman jabatan atau didasarkan atas hubungan baik antara atasan dengan bawahan. Dalam pelaksanaan mutasi harus benar-benar berdasarkan penilaian yang objektif dan didasarkan atas indeks prestasi yang dicapai oleh karyawan mengingat sistem pemberian mutasi dimaksudkan untuk memberikan peluang bagi para pegawai negeri sipil untuk mengembangkan potensi yang dimilikinya. Semangat kerja pegawai juga dapat menurun apabila pihak atasan tidak memperhatikan kepentingan para bawahan.

Hal ini akan menurunkan semangat kerja para pegawai (Hasibuan, 2008). Indikator dari turunnya semangat kerja antara lain rendahnya produktivitas, tingkat absensi pegawai tinggi, gaji rendah, dan lain-lain. Dengan demikian pastilah akan mempengaruhi semangat kerja pegawai dalam suatu organisasi. Pelaksanaan mutasi pada petugas puskesmas Beutong dilakukan setiap setahun sekali, mutasi dilakukan semata-mata sebagai bentuk penghargaan karena kedekatan hubungan dengan pimpinan 
serta hukuman bagi petugas yang berseberangan politik dengan penguasa tanpa memperhatikan bagaimana kinerja seorang petugas.

\section{Metodelogi Penelitian}

Jenis penelitian yang dilakukan yaitu Analitik dengan Desain Crossectional Yaitu penelitian yang bertujuan melihat ada tidaknya perbedaan atau hubungan antara variabel independen dengan variabel dependen (Notoatmodjo, 2005). Lokasi penelitian dilakukan di Puskesmas Kecamatan Beutong Kabupaten Nagan Raya. Penelitian ini dilakukan pada tanggal $12 \mathrm{~s} / \mathrm{d} 22$ November tahun 2014.

Populasi dalam penelitian ini adalah seluruh petugas Puskesmas Kecamatan Beutong Kabupaten Nagan Raya yang berjumlah 56 orang, yang terdiri dari Pegawai Negeri Sipil 36 orang serta Pegawai Tidak Tetap sebanyak 20 orang. Sampel adalah bagian dari populasi yang di harapkan mampu mewakili populasi dalam penelitian. Berdasarkan teori dari Arikunto (2003), apabila populasi di bawah 100 maka sampel yang di ambil adalah total sampling. Karena populasinya 56 orang, maka pengambilan sampel dalam penelitian ini adalah total sampling.

\section{Hasil Penelitian}

\section{Gambaran Umum Lokasi Penelitian}

Berdasarkan Penelitian yang telah dilaksanakan dari tanggal 12 - 22 November 2014 di Puskemas Beutong Kecamatan Beutong Kabupaten Nagan Raya yang memiliki tenaga kerja 95 Orang yang terdiri Pegawai Negeri Sipil (PNS) dan Pegawai Tidak Tetap (PTT) dan Tenaga Bakti. Jumlah PNS 36 orang dan PTT 20 orang dan Tenaga Bakti 39 Orang Puskesmas Beutong. 
Tabel 1. Sumber Daya Manusia (SDM) di Puskesmas Beutong Kecamatan Beutong Kabupaten Nagan Raya.

\begin{tabular}{|c|l|c|l|}
\hline No & \multicolumn{1}{|c|}{ Kualifikasi } & Jumlah & \multicolumn{1}{c|}{ Keterangan } \\
\hline 1 & Dokter Umum & 2 & 1 PNS, 1 PTT \\
\hline 2 & S1 Kesehatan Masyarakat & 3 & 1 PNS, 2 Bakti \\
\hline 3 & Akademi Keperawatan & 21 & 11 PNS, 9 Bakti \\
\hline 4 & Akademi Kebidanan & 49 & 13 PNS, 19 PTT,7Bakti \\
\hline 5 & Bidan D1 & 8 & 8 PNS \\
\hline 6 & SPRG & 2 & 2 PNS \\
\hline 7 & SMA/SMK & 5 & 5 Bakti \\
\hline 8 & Satpam & 1 & 1 Bakti \\
\hline 9 & Sopir & 2 & 2 Bakti \\
\hline 10 & Cleaning Service & 2 & 2 Bakti \\
\hline \multicolumn{2}{|c|}{ Total } & $\mathbf{9 5}$ & 36 PNS, 20 PTT, 39 Bakti \\
\hline
\end{tabular}

Sumber: Data Puskesmas Beutong (2014).

Puskesmas Beutong terletak di Gampoeng Lhok Seumot Kecamatan Beutong Kabupaten Nagan Raya. Puskesmas ini mempunyai wilayah kerja 24 desa yang ada di Kecamatan Beutong . Jarak dari Puskesmas ke Ibukota kabupaten Nagan Raya lebih kurang 30 km. Sedangkan luas wilayah kerja Puskesmas sekitar 1.323.06 KM.

Puskesmas Beutong berdiri tahun 2007 dengan luas bangunan kurang lebih 623 $\mathrm{m} 2$, ditambah tiga unit rumah dinas untuk dokter dan paramedis sehingga luas seluruhnya mencakup kurang lebih $1.344 \mathrm{~m} 2$. Lokasi Puskesmas Beutong berada di Jalan Ulee Jalan - Bumi Sari Gampong Padang Makmue km 05 Kecamatan Beutong Kabupaten Nagan Raya. Dengan Akses kejalan Nasional lebih kurang \pm 800 meter .Adapun batas-batas wilayah kerja Puskesmas Beutong adalah sebagai berikut: Timur berbatasan dengan Kecamatan Tadu Raya, Barat dengan Kecamatan Seunagan Timur, Utara dengan Kecamatan Beutong Benggalang, Selatan dengan Kecamatan Seunagan Timur.

\section{Analisis Univariat}

Analisis univariat digunakan untuk menggambarkan data responden dan variabel penelitian secara tunggal. Variabel penelitian terdiri dari mutasi dan cakupan pelayanan kesehatan. 
Tabel 2. Distribusi responden berdasarkan mutasi di Puskesmas Beutong Tahun 2014.

\begin{tabular}{cccc}
\hline No & Mutasi & Frekuensi & \% \\
\hline 1 & Ya & 37 & 66,1 \\
2 & Tidak & 19 & 33,9 \\
\hline & Jumlah & 56 & 100 \\
\hline
\end{tabular}

Sumber : Data primer diolah tahun 2014

Tabel 3. Distribusi responde n berdasarkan cakupan pelayanan kesehatan di Puskesmas Beutong Tahun 2014.

\begin{tabular}{cccc}
\hline No & $\begin{array}{c}\text { Cakupan Pelayanan } \\
\text { Kesehatan }\end{array}$ & Frekuensi & \% \\
\hline 1 & Tercapai & 44 & 78,6 \\
2 & Tidak Tercapai & 12 & 21,4 \\
\hline & Jumlah & 56 & 100 \\
\hline
\end{tabular}

Sumber : Data primer diolah tahun 2014

\section{Analisis Bivariat}

Tabel 4. Hubungan antara mutasi dengan cakupan pelayanan kesehatan di Puskesmas Beutong Tahun 2014.

\begin{tabular}{|c|c|c|c|c|c|c|c|c|c|}
\hline \multirow{3}{*}{ No } & \multirow{3}{*}{ Mutasi } & \multicolumn{4}{|c|}{$\begin{array}{c}\text { Cakupan Pelayanan } \\
\text { Kesehatan }\end{array}$} & \multicolumn{2}{|c|}{ Jumlah } & \multirow[t]{3}{*}{$\begin{array}{c}\mathbf{P} \\
\text { Value }\end{array}$} & \multirow[t]{3}{*}{ OR } \\
\hline & & \multicolumn{2}{|c|}{$\begin{array}{c}\text { Tidak } \\
\text { tercapai }\end{array}$} & \multicolumn{2}{|c|}{ Tercapai } & & & & \\
\hline & & $\mathbf{N}$ & $\%$ & $\mathbf{N}$ & $\%$ & $\mathbf{F}$ & $\%$ & & \\
\hline & $\overline{\text { Tidak }}$ & 9 & 47,4 & 10 & 52,6 & 19 & 100 & & \\
\hline & Ta & 3 & 8,1 & 34 & 91,9 & 37 & 100 & 0,001 & 10,2 \\
\hline & umlah & 12 & 21,4 & 44 & 78,6 & 56 & 100 & & \\
\hline
\end{tabular}

Sumber: data primer,2014 (diolah)

\section{Pembahasan}

Mutasi adalah suatu perubahan posisi/jabatan/tempat/pekerjaan yang dilakukan baik secara horizontal maupun vertikal di dalam satu organisai. Pada dasarnya mutasi termasuk dalam fungsi pengembangan karyawan, karena tujuannya untuk meningkatkan efisiensi dan efektivitas kerja dalam perusahaan (pemerintahan) tersebut. Dari hasil penelitian ini ditemukan adanya hubungan antara mutasi dengan cakupan pelayanan kesehatan. Hubungan antara mutasi dengan cakupan pelayanan kesehatan pada Puskesmas Beutong terlihat semakin termotivasinya kerja staf dikarenakan adanya kecocokan dengan jenis pekerjaan pada bagian baru dan kejenuhan dengan tugas la ma. 
Hal ini sesuai dengan teori Sastrohadiwiryo (2002), mutasi adalah kegiatan ketenagakerjaan yang berhubungan dengan proses pemindahan fungsi, tanggung jawab, dan status ketenagakerjaan tenaga kerja ke situasi tertentu dengan tujuan agar tenaga kerja yang bersangkutan memperoleh kepuasan kerja, semakin tinggi kepuasan kerja yang dimiliki staf puskemas Beutong, maka kinerjanya semakin baik sehinnga dapat memberikan prestasi kerja yang maksimal.

Hasil penelitian ini sama dengan hasil penelitian yang di lakukan Khairul pada Puskesmas Lampeuneurut tahun 2007. Berdasarkan penelitian Khairul, staf Puskesmas Lampeuneurut kebanyakan mengajukan diri untuk di mutasi ke bagian lain dengan alasan ingin mempelajari hal baru dan jenuh dengan pekerjaan lama. Hasil pene litian Khairul juga di dapatkan hubungan yang bermakna antara mutasi dengan cakupan pelayanan kesehatan dengan $P$ Value $(0,001)$.

Mutasi yang dilakukan di Puskesmas Beutong terbatas hanya dalam lingkup Puskesmas Beutong. Hal ini rutin dilakukan untuk mencegah kejenuhan dan menciptakan keadilan dikarenakan ada bagian-bagian tertentu dengan porsi pekerjaan yang besar dan ada yang kecil. Pada dasarnya perpindahan staf puskesmas Beutong dilandasi pada permintaan sendiri dan kebijakan pimpinan. Dengan adanya mutasi diharapkan dapat meningkatkan pengetahuan staf dan juga meningkat kinerja staf sehingga program yang ada di Puskesmas Beutong dapat tercapai, karena semakin banyak unit atau bagian yang pernah di bebankan padanya maka semakin beragam pula jenis pekerjaan yang diketahuinya.

\section{Kesimpulan}

Berdasarkan hasil penelitian diketahui adanya hubungan antara mutasi dengan cakupan pelayanan kesehatan di Puskesmas Beutong Kecamatan Beutong Kabupaten Nagan Raya $\mathrm{P}$ value $(0,001)<\alpha(0,05)$ artinya ada Hubungan yang signifikan antara mutasi dengan cakupan pelayanan kesehatan. 


\section{Daftar Pustaka}

Arikunto, 2002, Prosedur Penelitian Suatu Pendekatan Praktik, PT. Rineka Cipta. Jakarta.

Budiarto, Eko. 2001, Biostatistik untuk kedokteran dan Kesehatan Masyarakat. EGC, Jakarta.

Fathoni, 2006, Laporan Penelitian Pengaruh manajemen terhadap kedisiplinan Petugas Puskesmas Kecamatan Mampang Prapatan. Fakultas Kedokteran Universitas Indonesia (FKUI), Jakarta.

Hasibuan, M, 2008, Manajemen Sumber Daya Manusia. Aksara, Jakarta.

Kementerian Kesehatan no 129 tahun 2008, Kebijakan Revitalisasi PosyanduMelalui Pengembangan Desa Siaga.

Moekijat, 2005, Pelatihan Pegawai Untuk Memperoleh Efektivitas Dalam Pekerjaan, Jakarta.

Nasution, 2006, Manajemen Personalia. Badan Penerbitan Fakultas Ekonomi (BPFE). Yogyakarta.

Nitisemito, 2002, Pembangunan Masyarakat, Rineka Cipta, Jakarta.

Notoatmojo, S, 2005, Metodologi Penelitian Kesehatan. Jakarta, Rineka Cipta

Peraturan Pemerintah No. 43 tahun 1999, Pokok-Pokok Kepegawaian.

Peraturan Pemerintah No. 96 tahun 2000, Wewenang Pengangkatan, Pemindahan dan Pemberhentian Pegawai Negeri Sipil.

Sastrohadiwiryo, 2002, Dasar-dasar Metode Penelitian Klinis. Bagian Ilmu Kesehataan Anak FKUI, Bina Rupa Aksara, Jakarta.

Siagian, S, 2001, Teori Motivasi Dan Aplikasinya. Rineka Cipta. Jakarta.

Simamora, 2000, Teori dan Praktek Kepimpinan. Rineka cipta. Jakarta.

Siswanto, 2002, Administrasi Kepegawaian. Cetakan Pertama. Kanisius. Yogyakarta.

Sudarwan, 2004, Motivasi Kepemimpinan dan Efektifitas Kelompok. Rineka cipta. Jakarta. 